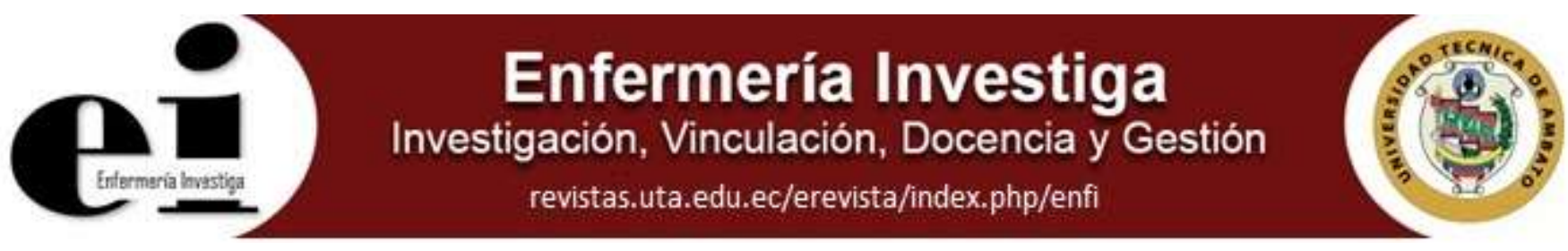

Artículo revisión

\title{
Infecciones asociadas a la atención en salud
}

Health care associated infections

\author{
Armindo Perozo-Mena ${ }^{1,2}$, Maribel Josefina Castellano González¹, Liliana Patricia Gómez Gamboa ${ }^{3}$ \\ ${ }^{1}$ Universidad del Zulia. Facultad de Medicina. Escuela de Bioanálisis. Departamento de Microbiología. Área de Bacteriología. Maracaibo-Zulia. Venezuela. \\ ${ }^{2}$ Hospital Universitario de Maracaibo, Centro de Referencia Bacteriológica. Maracaibo-Zulia. Venezuela. \\ ${ }^{3}$ Universidad del Zulia. Facultad de Medicina. Escuela de Medicina. Departamento de Enfermedades Infecciosas y Tropicales. Maracaibo-Zulia. Venezuela.
}

Perozo-Mena A., Castellano G.M.J., Gómez G.L.P. Infecciones asociadas a la atención en Salud. Enferm Inv. 2020; 5(2)48-61

2477-9172 / 2550-6692 Derechos Reservados (@) 2020 Universidad Técnica de Ambato, Carrera de Enfermería. Este es un artículo de acceso abierto distribuido bajo los términos de la Licencia Creative Commons, que permite uso ilimitado, distribución y reproducción en cualquier medio, siempre que la obra original es debidamente citada.

\section{Historia:}

Recibido: 05 enero 2020

Revisado: 10 febrero 2020

Aceptado: 27 febrero 2020

\section{Resumen}

En la actualidad, las infecciones asociadas a la atención en salud se consideran un problema de salud pública a nivel mundial, su aparición e incidencia es cada vez más frecuentes en las instituciones de salud, lo que ocasiona el aumento de las tasas de morbilidad y mortalidad, el aumento de los costos sanitarios y la disminución de la seguridad y calidad del servicio que se prestan. El riesgo de adquirir una de estas infecciones depende de la complejidad del servicio o intervención que se presta, su ubicación dentro de un hospital de alta complejidad o en un centro ambulatorio o externo, las condiciones o características individuales de cada paciente, los procedimientos o intervenciones que se realizan al paciente, el microorganismo responsable del cuadro, así como su patrón de sensibilidad y resistencia a los antibióticos. Por último, uno de los factores más importantes e influyentes para la adquisición de estas infecciones lo constituye la conducta del personal de salud, la aplicación adecuada de las medidas de contención primaria, el lavado correcto de las manos y la desinfección y/o esterilización del instrumental, equipos y ambientes hospitalarios, constituyen los factores determinantes más influyentes para la trasmisión de estas infecciones.

\section{Abstract}

At present, health associated care infections are considered a public health problem worldwide, its appearance and incidence in health institutions is increasingly frequent, causing increase in morbidity and mortality rates and health costs and the decrease in security and quality of service provided. The acquisition risk depends on the complexity of the service or intervention provided, its location within a highly complex hospital or in an outpatient or external center, the individual conditions of each patient, procedures or interventions that are performed, the microorganism responsible for the condition, as well as its pattern of sensitivity and resistance to antibiotics. Finally, one of the most important or influential factors for the acquisition of these infections is health personnel behavior, through the proper application of primary containment measures, adequate hand washing and disinfection and/or sterilization of instruments, equipment and hospital environments, these behaviors are the most influential determining factors for the transmission of these infections. 


\section{Introducción}

Las infecciones adquiridas en el hospital o infecciones intrahospitalarias están estrechamente ligadas a la institución hospitalaria. Existe evidencia de la existencia de instituciones hospitalarias o dedicadas al cuidado de la salud desde hace alrededor de 2.500 años, es decir, desde el siglo $V$ a.C. (1), por otra parte, las órdenes religiosas en Europa crean los primeros hospitales a principios del siglo XXII (2). La existencia de estas instituciones supone la aparición de los primeros casos de infecciones intrahospitalarias.

El término infecciones nosocomiales $u$ hospitalarias ha evolucionado a lo largo del tiempo hasta convertirse en "Infecciones Asociada a la Atención en Salud" (IAAS), esta nueva concepción, mucho más amplia, se hace en respuesta a la actual tendencia descentralizadora de las instituciones de salud, que ha permitido la creación de unidades o centros dedicados a prestar servicios específicos de salud fuera de una institución hospitalaria, como son los centros de diálisis, centros de cuidados prolongados para pacientes ancianos, terminales y psiquiátricos, centros de cirugía ambulatoria, centros de rehabilitación y unidades de cuidados ambulatorios, entre otras. En la actualidad ambos términos se siguen utilizando de manera intercambiable (3).

Las IAAS se describen por primera vez en el siglo XIX y han estado presentes en nuestras instituciones de salud en menor o mayor grado hasta la actualidad. La era antibiótica comienza en 1929 con el descubrimiento de la penicilina por Alexander Fleming, este descubrimiento contribuyo a la terapia efectiva de muchas infecciones, los antibióticos se utilizan con propósitos tanto terapéuticos como profilácticos, sin embargo, estos fármacos por sí solo no son capaces de controlar la aparición de IAAS (4).

A pesar del rápido desarrollo de la medicina, la erradicación de las IAAS sigue estando fuera del ámbito de esta. La medicina actual es más invasiva, lo que aumenta el riesgo de adquirir estas infecciones al proporcionar más oportunidades a los microorganismos patógenos, oportunistas o comensales; otro factor importante a considerar lo constituye el aumento de la proporción de pacientes neonatos y adultos mayores, así como inmunocomprometidos en los hospitales, los cuales corren un mayor riesgo de contraer infecciones en estos ambientes (4).

La literatura describe muchos casos de IAAS en establecimientos de salud, su distribución y etiología varía ampliamente en las diferentes instituciones y ubicaciones geográficas; sin embargo, los cuadros que generalmente se presentan en casi la totalidad de las instituciones, especialmente en hospitales que ofrecen servicios de cuidados agudos son: infección quirúrgica de heridas, neumonía asociada a ventilación mecánica, infección del tracto urinario, infección del torrente sanguíneo e infecciones asociadas a dispositivos. La mayor parte de estas infecciones se deben a factores de riesgo que favorecen la adquisición de microorganismos patógenos (4-9).

Las IAAS poseen una naturaleza dinámica, los protagonistas son los pacientes, los visitantes y el personal de salud, mientras que los escenarios están constituidos por las instituciones de salud y el ámbito comunitario $(4,5,9)$. Esta relación dinámica entre protagonistas y escenarios permite a los pacientes, el personal o los visitantes importar cualquier tipo de infección al hospital, contraer infecciones dentro del hospital y transportar agentes infecciosos a otros hospitales o a la comunidad. Esto hace que el control de las IAAS sea complejo ya que se deben controlar un gran número de variables $(5,9)$.

El término "infección nosocomial" suele restringirse exclusivamente a las infecciones que los pacientes adquieren en el ámbito de una institución prestadora de servicios de salud (IPSS). El desarrollo de infecciones sigue ciertas reglas bien definidas, que deben conocerse para realizar una adecuada prevención. Estas reglas se aplican a las IAAS tanto de origen hospitalario como a las adquiridas en la comunidad, sin embargo, las IAAS poseen ciertos factores específicos que las diferencian, como el uso de procedimientos médicos invasivos, uso de antibióticos de amplio espectro, así como estancias hospitalarias prolongadas (4).

El control, vigilancia y prevención de las IAAS en los últimos años se ha hecho más complejo, esta complejidad se debe principalmente a la reducción de las estancias hospitalarias, atención primaria y domiciliaria o fuera del ámbito hospitalario, el aumento de pacientes ancianos y con afecciones más graves, la aparición de los centros de cuidados ambulatorios y prolongados, así como a la aparición de enfermedades emergentes y microorganismos multirresistentes a los antibióticos. Este contexto ha hecho que los profesionales de la salud que participan en el control de infecciones deban asumir otras responsabilidades adicionales al control de infecciones, como son la seguridad del paciente y la calidad de la asistencia prestada.

A raíz de estas consideraciones, algunas organizaciones siguieren que la asignación de profesionales dedicados al control de infecciones no debe basarse en el número de camas que tendrá a cargo, sino en la complejidad de las funciones que realizará. Para ello se deberán establecer criterios para seleccionar los indicadores de control de infecciones más adecuados y se tendrá que demostrar la relación costo-beneficio de estos programas (10).

Las IAAS constituyen la principal causa prevenible de eventos adversos graves en pacientes que asisten a instituciones prestadoras de servicios de salud, produce efectos incalculables en las vidas de las personas atendidas y deterioran la imagen de los equipos asistenciales, de las instituciones prestadoras de servicios de salud y de los sistemas sanitarios, adicionalmente, producen un gran impacto en la economía de los países y dificultan la 
sostenibilidad de los programas de salud (11). Las IAAS se han identificado como uno de los principales problemas de salud pública y debe enfatizar la importancia de implantar sistemas de prevención y control que permitan mejorar la calidad asistencial en los centros sanitarios (11).

Esta revisión tiene como objetivo proporcionar una introducción básica de las IAAS, los aspectos más relevantes que permitan comprender los principios generales, su dinámica, protagonistas, así como las medidas de prevención y control, para de esta manera disminuir su incidencia y mejorar la calidad de atención prestada a los pacientes en las instituciones prestadoras de servicios de salud.

\section{Definiciones}

\section{Infecciones Asociadas a la Atención en Salud (IAAS)}

El término infecciones nosocomiales (del latín nosocomium, "hospital") se refiere a infecciones adquiridas durante la estancia en una IPSS y que estaban ausentes en el período de incubación y en el momento del ingreso del paciente $(12,13)$, por regla general, las infecciones que ocurren en un lapso de $48 \mathrm{~h}$ después del ingreso suelen considerarse nosocomiales.

En la actualidad el concepto ha evolucionado a "Infecciones asociadas a la atención en salud o sanitaria", ya que este tipo de infecciones claramente ha traspasado el ámbito de los hospitales. Los recientes avances tecnológicos han facilitado prolongar la vida hasta edades avanzadas, también han permitido que la asistencia sanitaria pueda prestarse en entornos no estrictamente hospitalarios, como los centros ambulatorios donde se practican técnicas diagnósticas, procedimientos de hemodiálisis e intervenciones quirúrgicas ambulatorias, se efectúan tratamientos endovenosos en el domicilio, o ingresan a instituciones sanitarias que se encargan de prestar atención sanitaria con cierto grado de complejidad a enfermos crónicos o convalecientes.

El término "Infecciones relacionadas o asociadas con la asistencia sanitaria" fue acuñado por Friedman et al (14), quienes describieron casos de bacteriemia en pacientes de la comunidad (no hospitalizados) pero en contacto estrecho con el sistema sanitario, los casos tenían un foco y etiología muy semejante a la bacteriemia de los pacientes ingresados en el hospital y por el contrario, fueron muy diferente las bacteriemias adquiridas en la comunidad por pacientes sin ningún contacto con el sistema sanitario.

\section{Infección y Colonización}

Los términos infección, enfermedad infecciosa, infección subclínica y colonización frecuentemente son utilizados de manera indistinta, sus definiciones tienden a confundirse, sin embargo, se deben consideran como términos diferentes con pequeñas sutilezas que permiten su diferenciación.

Una infección implica la multiplicación exitosa de un microorganismo sobre o en el interior de un hospedador. Por otra parte, el término enfermedad infecciosa aplica cuando un hospedador presenta signos y síntomas producto de una infección $(3,7)$; se puede observar que la principal diferencia entre los dos términos es la presencia de alteraciones fisiopatológicas que se manifiestan en forma de signos y síntomas.

Si la infección solo produce una respuesta inmune en el hospedador sin manifestaciones clínicas, se considera una infección subclínica o infección inaparente. La colonización por otra parte implica la presencia de un microorganismo dentro o sobre un hospedador, dicho microorganismo adicionalmente posee la capacidad de crecer y multiplicarse en el hospedador, pero sin expresión de una respuesta clínica o producción de una reacción inmune detectable en el momento de su aislamiento $(3,15)$.

Por lo tanto, una infección subclínica o inaparente no es más que la relación que se establece entre un hospedador y un microorganismo, en la que no existe expresión de respuesta clínica debido a la presencia del microorganismo (signos y síntomas), pero la interacción existente entre ambos genera una respuesta inmune que puede generar reacciones serológicas, la conversión en pruebas a nivel de piel o una respuesta proliferativa de glóbulos blancos que genere la formación de anticuerpos contra el microorganismo infectante. Por lo tanto, para diferenciar colonización de infección subclínica se debe contar con pruebas serológicas que sean capaces de medir la respuesta inmune del hospedador (3).

Un portador $u$ hospedador colonizado no es más que, un individuo colonizado con un microorganismo específico que puede ser recuperado mediante cultivo, sin embargo, dicho hospedador no muestra ningún tipo de respuesta debido a la presencia del microorganismo al momento de su aislamiento (3).

La colonización es un proceso natural que permite el desarrollo e instauración de la microbiota normal. En las IAAS la colonización juega un papel primordial en el desarrollo y diseminación del microorganismo; en la mayoría de los casos la colonización es un precedente necesario para el desarrollo de una infección, la colonización de piel y mucosas permite sustituir los microorganismos de la microbiota normal por microorganismos patógenos, que pueden ocasionar enfermedades infecciosas. Algunos autores consideran que es importante diferenciar dentro de las IPSS poblaciones o subpoblaciones de pacientes colonizados por microorganismos patógenos, especialmente 
microorganismos multiresistentes a los antibióticos, ya que estos pacientes colonizados sirven de reservorio o fuente de infección a otros pacientes o como fuente de contaminación de ambientes o equipos médicos $(3,7,8,15,16)$.

\section{Perspectiva Histórica}

Selwyn (1) indica que para el año 500 a.C. existían hospitales organizados para el cuidado de las enfermedades existentes en el mundo civilizado, estaban ubicados mayoritariamente en India, Egipto, Palestina y Grecia, las condiciones higiénicas prevalentes de dichos hospitales tenían como base los principios religiosos de las culturas orientales como son los rituales de pureza del cuerpo, dichos principios han demostrado ser superiores a los aplicados durante los últimos 100 años en los hospitales creados en la Europa Cristiana los cuales constituyen la base de los hospitales actuales. La filosofía del cristianismo se oponía al lavado y cuidado del cuerpo, San Jerónimo en el siglo 4 d.C. afirmaba que "quien había sido lavado en cristo nunca necesitaría lavarse nuevamente"; para el cristianismo la mortificación de la carne era la regla y el "olor a santidad" debía ser real, el alma era más importante que el cuerpo y la mayoría de los hospitales administrados por la iglesia se encargaban principalmente de la sanación del alma y no del cuerpo (1)

Los datos más antiguos sobre la construcción y condiciones de higiene de los hospitales están contenidos en el Charaka-Samhita, un libro de texto sobre medicina escrito en sanscrito el cual probablemente fue escrito en el silo IV a.C. Este texto detalla la estructura, organización y práctica realizadas en dichos hospitales, funcionaban en mansiones especialmente construidas para este fin y su edificación era supervisada por un ingeniero, debía ser espacioso, una porción del edificio debía estar abierta a las corrientes de aire y los pacientes no debían estar expuestos al humo, polvo, sonidos dañinos o estar en contacto o ingerir esencias de ningún tipo; adicionalmente se debía asegurar un cuerpo de personas dedicadas al cuidado de los pacientes que fueran de buenas costumbre y distinguidos por la pureza y limpieza de sus hábitos (17). Las instituciones diseñadas en base a estas características permitían el eficiente control de las IAAS y su reflejo fue el gran número de intervenciones quirúrgicas realizadas en ellas entre las que se incluyen cirugías oculares y cirugías plásticas y reconstructivas $(1,17)$.

Los griegos en el siglo $V$ a.C. no poseían los recursos quirúrgicos de los hindúes, pero poseían imponentes hospitales adyacentes al templo de Asklepios (Aesculapius para los romanos), sus recintos poseían cámaras dormitorios muy espaciosas y bien aireadas (1).

En el caso de los antiguos judíos, la propagación de las enfermedades era prevenida mediante la aplicación inflexible de las leyes del Leviticus (tercer libro del viejo testamento), para la época no solo tenían parámetros estrictos para la higiene general, sino que se encargaban de realizar el diagnóstico de las infecciones o "impurezas" de la piel, el aislamiento de los pacientes infectados y la destrucción de los fómites del paciente. En el libro del Talmud existen instrucciones para la prevención de las infecciones transmitidas por el aire, se advierte a los cirujanos que no deben tocar las heridas debido a que las manos causan inflamación $(1,2)$.

Las prácticas, estructura y diseño de las instalaciones de cuidados para la salud de los antiguos hospitales orientales cumplen con la mayoría de los preceptos utilizados para el control de infecciones en la actualidad. Estos altos estándares de los griegos y judíos fueron mantenidos en los hospitales romanos, especialmente en los hospitales del ejército los cuales consistían en un edificio bordeando un patio central, las habitaciones estaban diseñadas para uno o dos pacientes y donde estudios arqueológicos indican que el instrumental quirúrgico y las vestimentas probablemente eran calentados a altas temperaturas en un horno antes de su uso $(1,2)$.

Desafortunadamente hubo un deterioro de la higiene en Europa con la caída del imperio romano a principios del siglo $\mathrm{V}$ d.C.; debido principalmente al modo de vida relativamente primitivo de las poblaciones locales y el dominio, para la fecha, de las tribus bárbaras invasoras; otro elemento clave en la configuración de las instituciones de salud lo constituye el espectacular ascenso al poder de la cristiandad, el cual fue un factor determinante importante en la estructura y prácticas de los hospitales del mundo occidental (1).

En las primeras enfermerías de los monasterios predominaba la pestilencia y la falta de higiene. Los primeros reformistas de los hospitales tuvieron poco o ningún éxito. En el siglo XIII Teodoro de Bologna deploraba la corriente de enseñanza que afirmaba que la "loable pus" era un prerrequisito para la curación de las heridas, el cuidadosamente limpiaba las heridas y las suturaba para evitar la contaminación por el aire, estas medidas aparentemente evitaban la supuración en la mayoría de sus casos (18), como resultado de su trabajo pionero en el área de cirugía aséptica, Teodoro fue perseguido por sus colegas y denunciado como hereje por la iglesia.

Otro pionero ignorado por la medicina fue el cirujano alemán Caspar Stromayr, fue un experto en la reparación quirúrgica de hernias, dentro de su plan de trabajo eran importantes el baño de sus pacientes y la depilación del área quirúrgica, prácticas no aceptadas o empleadas para la época; por otra parte Ambroise Pare, contemporáneo de Stromayr, realizaba un tratamiento gentil de las heridas traumáticas basado en el desbridamiento del tejido desvitalizado y el vendaje de las heridas, abandonando el uso rutinario para la época de aceite hirviente y la cauterización mediante hierro al rojo vivo, estas prácticas le permitieron alcanzar una relativamente baja tasa de infección de heridas. A pesar de que la implementación de estas prácticas demostraba una disminución en las tasas 
de infección en los pacientes debieron pasar trescientos años para que las mismas fueran aceptadas e implementadas rutinariamente en la medicina $(1,19)$.

Los primeros estudios científicos sobre infecciones cruzadas hospitalarias o nosocomiales se realizaron en la primera mitad del siglo XVIII, en 1740 John Pringle pionero de la antisepsia crea el término "fiebre hospitalaria" y lo relaciona con condiciones de higiene de los hospitales, también se crean las primeras salas de aislamiento, se descubre la naturaleza transmisible de la fiebre puerperal y sus medidas de control, se determina que la calidad del aire está relacionada con las infecciones, se establecen los principios de la sepsis quirúrgica y se establecen las medidas asépticas para su control, se investigan las infecciones hospitalarias como una entidad prevalente, se descubre y nombra al grupo estafilococos como agentes etiológicos lo que constituye el nacimiento de la bacteriología de la supuración, lo que trae como consecuencia la creación de los primeros laboratorios de bacteriología hospitalaria (1).

En la segunda mitad del siglo XIX nace la teoría microbiana de la enfermedad o teoría germinal de las enfermedades infecciosas la cual propone que los microorganismos son la causa de una amplia gama de enfermedades, estos invaden a un hospedador susceptible, donde crecen y se multiplican dentro del hospedador y pueden en ocasiones producir enfermedad. Aun cuando esta teoría establece que el patógeno es la principal causa de una enfermedad infecciosa, existen otros factores personales como la herencia genética, nutrición, fortaleza o debilidad del sistema inmunológico, ambiente y hábitos higiénicos que a menudo influencian la severidad de la enfermedad y la probabilidad de que un individuo en particular se infecte tras ser expuesto al patógeno.

Esta teoría fue demostrada por Louis Pasteur y reemplazó las concepciones de enfermedad que se tenían para la época como la teoría miasmática o la teoría de los humores. Aunque fue muy controvertida cuando se propuso, es ahora fundamental en la medicina moderna y la microbiología clínica, conduciendo a innovaciones tan importantes como el desarrollo de las vacunas, los antibióticos, la esterilización y la higiene como métodos efectivos contra la propagación de enfermedades contagiosas $(20,21)$. Todas estas experiencias contribuyeron a dar forma a la actual concepción de las IAAS, así como a los principios utilizados para su diagnóstico, prevención y control.

\section{Incidencia de las IAAS}

Las IAAS se presentan en un 5 a $10 \%$ de los pacientes que ingresan a una institución de salud (22), el desarrollo de estas infecciones está relacionado con factores como la edad (siendo más frecuentes en los extremos de la vida) y el estado inmunitario, ya que estas condiciones hacen que los pacientes sean más susceptibles a padecer infecciones. Otro aspecto por considerar lo constituye el destino o servicio de hospitalización del paciente, servicios como unidades de terapia intensiva, quemados y servicios quirúrgicos son las áreas hospitalarias en las que se presentan más frecuentemente este tipo de infecciones.

Actualmente se estima que la IAAS más frecuente es la infección urinaria producida por el uso de catéteres o sondas de vía urinaria (40\%) (23), en segundo lugar, se encuentra la infección de heridas quirúrgicas la cual representan hasta un $25 \%$ de las IAAS, las infecciones respiratorias se estima que se presentan de un 15 a $20 \%$, mientras que, las infecciones asociadas a cateterismo representan un 10\% (23-28). Sin embargo, la distribución de las distintas IAAS depende de la institución y del servicio de internación, por ejemplo, la estancia en unidades de terapia intensiva eleva el riesgo de adquirir una infección IAAS hasta en 7,4 veces, de manera que la distribución de las IAAS dentro de este servicio cambia por lo que podemos encontrar en el $40 \%$ de los casos neumonías asociadas a ventilación mecánica, las bacteriemias se ubican en segundo lugar con un 25 a 30\%, mientras que las infecciones urinarias, infecciones de heridas quirúrgicas y otros tipos de infecciones en conjunto representan tan solo un 30\% (29).

El estudio de prevalencia de infección nosocomial en España (30) y el Point Prevalence Study efectuado en diversos países de Europa (31), establece una tasa de adquisición de IAAS de aproximadamente en el 7\% de los pacientes que reciben servicios de salud. Los resultados de estos estudios han permitido identificar la frecuencia y fuente de la infección nosocomial en Europa. Hasta hace algunos años, como lo demuestran otros estudios (23), las infecciones del tracto urinario constituían la IAAS más prevalente, sin embargo, en la actualidad esta ha sido desplazada por las infecciones del tracto respiratorio, seguida de las infecciones de sitio quirúrgico en el caso del estudio europeo (31), mientras que, en el estudio español, las infecciones urinarias ocupan el segundo lugar (30). Estos datos indican que la prevalencia de estas infecciones depende de los factores locales propios de cada institución o zona geográfica.

Las principales consecuencias asociadas a las IAAS es la elevada mortalidad, así como la prolongación de la estancia hospitalaria y el aumento de los costos asistenciales. Según datos estimados por el National Nosocomial Infection Surveillance System (NNIS), en el año 2002 se produjeron más de 1,7 millones de IAAS y alrededor de 100.000 muertes anuales por esta causa en Estados Unidos. Esto sitúa a las IAAS dentro del grupo de las 10 causas más frecuentes de muerte en dicho país (32). Por otra parte, un estudio realizado por Zhang y col (33) en Beijing, China, muestra que para el año 2013 la tasa de IAAS fue de 4,10/1000 pacientes por día mientras que para el año 2017 fue de 3,62/1000 pacientes por día, lo que demuestra que la incidencia es dinámica y varía en función de la 
localización y de la gravedad de la infección $(34,35)$, se calcula que el costo directo de estas infecciones en Estados Unidos es de cientos de miles de millones de dólares, sin incluir los costes indirectos producto de la baja productividad de los pacientes y familiares (36).

La erradicación total o la reducción permanente de la tasa de IAAS a cero es una utopía. Esto se debe a la presencia constante del riesgo inherente a cualquier procedimiento médico invasivo realizado durante la hospitalización; a pesar de esto, es posible la eliminación, entendida como la reducción al máximo del número de IAAS mediante un esfuerzo coordinado y continuado de prevención por parte del personal de salud y las autoridades sanitarias. Se estima que los programas de prevención y control de IAAS pueden evitar aproximadamente el $65 \%$ de las infecciones del tracto urinario y bacteriemias, así como el $55 \%$ de las infecciones de sitio quirúrgico y neumonías, lo que permitiría salvar miles de vidas y ahorrar millones de dólares en costo de atención en salud (37).

\section{Factores asociados al desarrollo de IASS}

Por lo general las IAAS se relacionan con procedimientos médicos invasivos como infección de sitio quirúrgico después de un procedimiento quirúrgico, infección urinaria nosocomial debida a cateterismo urinario, infección respiratoria debida a ventilación mecánica invasiva y bacteriemia ocasionada por el uso catéteres vasculares centrales y periféricos $(5,28,38,39)$. Todos estos cuadros tienen en común la disrupción de las defensas naturales del hospedador por el uso de un dispositivo o una incisión, permitiendo que los microorganismos que forman parte del microbiota normal del paciente (flora endógena) invadan los tejidos, en ocasiones el tratamiento previo con antibióticos ejerce presión selectiva sobre la microbiota normal del hospedador, lo que permite seleccionar microorganismo resistente a los antibióticos que posteriormente producen infección. Por otra parte, los microorganismos que forman parte de la microbiota del entorno o ambiente hospitalario inanimado (flora exógena), puede en determinadas ocasiones colonizar al paciente y producirle infecciones.

La probabilidad de adquisición de una IASS está relacionada con diversos factores predisponentes. Existe una correlación directa positiva entre la estancia hospitalaria en unidades de cuidados intensivos y la tasa de padecimiento de una IAAS (40), cada procedimiento médico invasivo que se realiza al paciente tiene su propio riesgo de infección. Múltiples estudios han demostrado que la utilización de catéteres venosos centrales, ventilación mecánica, traqueostomías y procedimientos quirúrgicos incrementan el riesgo de padecer una IAAS $(4,14,23,28,40$ 45).

\section{Factores condicionantes para la adquisición de IAAS}

Adicionalmente a los factores predisponentes, existen los llamados factores condicionantes para la adquisición de IAAS, estos factores son el agente etiológico, la vía de transmisión y las condiciones del hospedador. En cuanto al hospedador, la evolución y desarrollo del proceso infeccioso está determinado directamente por la resistencia a la infección, el estado inmunológico y nutricional, el estrés, la edad, el sexo, días de estancia hospitalaria y la enfermedad de base por la cual ingresó a la institución (22). Otras condiciones del hospedador que predisponen a la adquisición de IAAS son los trastornos de la deglución presentes en pacientes, que han sufrido accidentes cerebro vasculares, dichos trastornos predisponen a un mayor riesgo de sufrir infecciones respiratorias por aspiración. La colonización frecuente por Staphylococcus aureus en pacientes con insuficiencia renal crónica, diabetes mellitus o insuficiencia hepática supone un mayor riesgo de infección por este agente durante el ingreso a una institución de salud (22).

En cuanto a la vía o mecanismo de transmisión, se ha identificado en la mayoría de los casos al personal encargado de los pacientes como reservorio y/o vector de brotes y epidemias de IAAS, por lo que las técnicas y procedimiento que realizan de manera rutinaria en el paciente como cateterismo venoso, sondaje vesical junto a manipulación de vías urinarias, intubación endotraqueal, entre otros; así como también la vigilancia de la terapia farmacológica, y técnicas de asepsia y antisepsia en todo procedimiento se convierten en factores claves para el desarrollo o no de las IAAS (46). Mientras que, por parte del agente etiológico, características como infectividad, patogenicidad y virulencia, así como los patrones de sensibilidad o resistencia a los agentes antimicrobianos (22).

\section{Etiología bacteriana de las IAAS}

Los microorganismos asociados a IAAS pueden proceder de fuentes exógenas o endógenas como se indicó anteriormente. Los asociados a fuentes endógenas se encuentran formando parte del microbiota normal del paciente, como en el caso del tracto intestinal; por otra parte, la contaminación o fuente exógena de infección se produce cuando el microorganismo proviene de una fuente externa, como la microbiota normal residente en las manos y la piel del personal de salud, el instrumental, equipos médicos o medio ambiente hospitalario contaminados $(22,38)$. 
La etiología de las IAAS ha presentado variaciones a lo largo del tiempo. Al principio los patógenos predominantes eran las bacterias Gram positivas, sin embargo, con la introducción de los antibióticos y la consecuente disminución de las IAAS causadas por estos microorganismos produjo un cambio en la etiología y estas pasaron a ser producidas principalmente por bacterias Gram negativas. A finales del siglo XX las bacterias Gram positivos reaparecen como patógenos predominantes en algunas partes del mundo. Adicionalmente, se incrementan los casos de IAAS producidas por hongos, sin embargo, hasta el presente las bacterias Gram negativas continúan siendo los principales agentes productores de estos cuadros a nivel mundial (46).

Entre los principales bacilos Gram negativos involucrados tenemos Pseudomonas aeruginosa, Enterobacterias como Klebsiella pneumoniae, Enterobacter spp. y Escherichia coli. Entre los bacilos Gram positivos encontramos las especies de Clostridium, entre los cocos Gram positivos tenemos a los Streptococcus $\beta$ hemolíticos, Streptococcus pneumoniae, Staphylococcus aureus y Enterococos. Mientras que, entre los hongos encontramos especies de Candida como C. albicans y C. glabrata. En el caso de las IAAS es importante aclarar que una infección puede ser causada por más de un microrganismo patógeno y que un mismo agente puede ocasionar múltiples infecciones $(22,29,30,38,47-49)$.

La Red Nacional de Seguridad para el Cuidado de la Salud (National Healthcare Safety Network [NHSN]), programa de vigilancia de las IAAS en Estados Unidos, incorpora datos microbiológicos en sus informes acumulados, estos datos aportan información sobre la frecuencia de los diferentes microorganismos productores de IAAS en función del sitio de infección (50). Según el reporte, la mayor parte de las IAAS están ocasionadas por un grupo de ocho microorganismos, la frecuencia relativa de los diferentes microorganismos varía en función del foco de infección, por ejemplo S. aureus es el agente más frecuente de neumonía asociada a ventilación mecánica y de infecciones de sitio quirúrgico, mientras que Escherichia coli está más asociada a infecciones del tracto urinario, por otra parte los estafilococos del grupo coagulasa negativa están frecuentemente asociados a bacteriemia. Disponer de esta información es importante desde el punto de vista clínico y epidemiológico, especialmente si se considera que estos microorganismos generalmente presentan problemas de resistencia a los antibióticos.

En las últimas décadas se ha observado una tendencia al aumento progresivo de la resistencia a múltiples antibióticos por parte de los bacilos gramnegativos, especialmente en los miembros del orden Enterobacterales y en bacilos no fermentadores de la glucosa como Pseudomonas y Acinetobacter, esta tendencia en aumento está relacionada principalmente con la presión selectiva ejercida producto del uso inadecuado e indiscriminado de antibióticos de amplio espectro (15,46,47,50-53). Al igual que la etiología, las tasas de sensibilidad y resistencia a los agentes antimicrobianos pueden variar enormemente de un país a otro, de una localidad o comunidad a otra dentro de un mismo país e incluso entre dos IPSS cercanas dentro de una ciudad, se hace importante disponer de datos locales de etiología y resistencia que permitan establecer estas tendencias.

El patrón de colonización por microorganismos intrahospitalarios en los pacientes críticos es diferente al del resto de la población hospitalaria. Los patógenos nosocomiales colonizan a estos pacientes de 48 a 72 horas después de su admisión a unidades de terapia intensiva o cuidados especiales, otra característica importante en esta población es el hecho de que estos colonizantes poseen tasas de resistencia a los antibióticos mucho más altas (39). La resistencia se debe principalmente a la presión selectiva ejercida por el uso rutinario de agentes antimicrobianos en estos servicios los cuales obligan a las bacterias existentes tanto en los pacientes como en el ambiente a evolucionar y desarrollar mecanismos de resistencia. A este problema se agrega la transmisión intrahospitalaria de estos microorganismos resistentes, dicha transmisión desafortunadamente involucra en la mayoría de los casos al personal de salud y la realización de procedimiento invasivos $(7,39,45)$.

En cuanto a los mecanismos de resistencia presentes en los microorganismos productores de IAAS, especialmente en las unidades de terapia intensiva encontramos; Staphylococcus aureus resistente a la meticilina (54-57), Enterococcus resistente a la vancomicina (58-61), Enterobacterales productores de betalactamasas de espectro extendido (62-70), bacilos Gram negativos productores de carbapenemasas y/o multirresistentes (71-79), y especies de Candida con resistencia a los azoles (80-86).

La presencia de estos microorganismos multirresistentes como productores de IAAS genera consecuencias clínicas negativas importantes, estos microorganismos a nivel de laboratorio demoran más tiempo en ser cultivados e identificados, lo que ocasiona una demora en la aplicación de una terapia oportuna optima al paciente, por otra parte, para su tratamiento se deben utilizar agentes terapéuticos como vancomicina, linezolid y daptomicina, los cuales se asocian frecuentemente con toxicidad y son menos efectivos desde el punto de vista farmacocinético y farmacodinámico. La incidencia de estos microorganismos puede reducirse en las unidades de cuidados críticos mediante el uso racional de antibióticos, a pesar de que inicialmente se requiera el uso de antibióticos de amplio espectro, una vez identificado el microorganismo y conocida su susceptibilidad, se debe cambiar el tratamiento tan pronto como sea posible a un espectro más reducido y específico para el microorganismo aislado. 


\section{Medidas de control}

Los métodos para el control y prevención de las IAAS son tan variados y complejos como las infecciones mismas, estos abarcan aspectos de ingeniería como el diseño y mantenimiento de las instalaciones, hasta decisiones administrativas relacionadas con las políticas de inmunizaciones y la higiene personal de los trabajadores de salud y pacientes $(15,40,87)$.

En virtud de los costos que representan las IAAS en el sentido económico y de vidas humanas, la mejor y principal medida a adoptar para el control de las mismas es la prevención. Las medidas preventivas se dan en base a la infección que se quiere evitar, pero también existen ciertas normas a seguir que son aplicables para todos los casos (88). La Tabla 1 muestra las principales intervenciones que pueden aplicarse en las IPSS para controlar las IAAS. Intervenciones como esterilización de instrumental quirúrgico y utilización de técnicas asépticas en el cuidado de heridas se han utilizado desde hace mucho tiempo, por el contrario, otras medidas como el lavado obligatorio de manos y la restricción en el uso de antibióticos son más nuevas y en ocasiones son difíciles de implementar, ya que tienden a crear resistencia en el personal de salud, debido principalmente a que son contrarias a hábitos, costumbres y prácticas de larga data en la institución.

\section{Tabla 1. Medidas Recomendadas para el Control y Prevención de IAAS}

\begin{tabular}{|c|c|}
\hline $\begin{array}{l}\text { Limpieza/lavado de manos } \\
\text { (antes y después de tener } \\
\text { contacto con un paciente) }\end{array}$ & $\begin{array}{l}\text { Esta es la medida individual más importante para prevenir la propagación de } \\
\text { microorganismos, especialmente } S \text {. aureus resistente a la meticilina. Una } \\
\text { alternativa al lavado de manos es la descontaminación con alcohol-gel u otro } \\
\text { desinfectante, sin embargo, este debe ser utilizado solo cuando la carga de } \\
\text { contaminación es baja, en caso de ser alta se debe emplear el lavado de manos; } \\
\text { otros aspectos a considerar es que estas sustancias o desinfectantes no son } \\
\text { capaces de eliminar las esporas ( } C \text {. difficile) y no afectan a virus como los } \\
\text { Norovirus }\end{array}$ \\
\hline Enfoque aséptico & $\begin{array}{l}\text { La inserción y manejo de dispositivos intravasculares y catéteres urinarios deben } \\
\text { manejarse en condiciones asépticas o de esterilidad total }\end{array}$ \\
\hline Aislamiento protector & $\begin{array}{l}\text { Algunos pacientes, especialmente los inmunocomprometidos se deben aislar } \\
\text { para protegerlos de las infecciones, este enfoque es diferente al que } \\
\text { generalmente se emplea en el cual se proteger a los contactos en lugar de los } \\
\text { pacientes }\end{array}$ \\
\hline $\begin{array}{l}\text { Aislamiento y barrera de } \\
\text { enfermería }\end{array}$ & $\begin{array}{l}\text { En el caso de pacientes infecciosos (por ejemplo, tuberculosis, MRSA o diarrea } \\
\text { activa) el personal de enfermería debe proteger al resto de los pacientes y aplicar } \\
\text { técnicas de aislamiento para evitar la propagación del microorganismo dentro del } \\
\text { servicio o la unidad }\end{array}$ \\
\hline $\begin{array}{l}\text { Descontaminación } \quad \text { de } \\
\text { equipos médicos }\end{array}$ & $\begin{array}{l}\text { Los equipos médicos como los endoscopios generalmente no resisten la } \\
\text { esterilización en autoclave y a menudo, tienen canales complejos difíciles de } \\
\text { limpiar, por lo que se hace necesario para realizar su limpieza utilizar técnicas de } \\
\text { desinfección. Si la técnica no se realiza de manera correcta o se utiliza un } \\
\text { desinfectante inadecuado, estos equipos se pueden convertir en un riesgo } \\
\text { importante de transmisión de infección }\end{array}$ \\
\hline $\begin{array}{l}\text { Esterilización } \\
\text { instrumental quirúrgico y } \\
\text { empleo de técnicas } \\
\text { asépticas }\end{array}$ & $\begin{array}{l}\text { La correcta y adecuada esterilización del instrumental y equipos quirúrgicos, así } \\
\text { como la implementación de técnicas asépticas reduce el riesgo de las heridas de } \\
\text { los pacientes a microorganismos patógenos }\end{array}$ \\
\hline Uso racional de antibióticos & $\begin{array}{l}\text { Se deben implementar en las instituciones un programa de uso racional de } \\
\text { antibióticos con guías para la utilización de estos, todo el personal debe adherirse } \\
\text { estrictamente al cumplimiento de estas guías con el fin de reducir la selección de } \\
\text { microorganismo resistentes }\end{array}$ \\
\hline $\begin{array}{l}\text { Profilaxis antibiótica } \\
\text { preoperatoria }\end{array}$ & $\begin{array}{l}\text { Esta medida ayuda a prevenir la infección asociadas a heridas quirúrgicas, } \\
\text { particularmente en sitios anatómicos donde hay una microbiota normal } \\
\text { significativa (por ejemplo, cirugía abdominal), o cuando las consecuencias de la } \\
\text { infección pueden ser catastróficas (por ejemplo, cirugía de injerto vascular). Una } \\
\text { precaución que debe tomarse con esta medida es vigilar la no sobre utilización } \\
\text { de estos agentes, así como la no utilización de agentes antimicrobianos de }\end{array}$ \\
\hline
\end{tabular}




\begin{tabular}{|c|c|}
\hline & $\begin{array}{l}\text { amplio espectro como carbapenemas, vancomicina y linezolid, entre otros, como } \\
\text { agentes profilácticos }\end{array}$ \\
\hline $\begin{array}{l}\text { Correcta disposición de } \\
\text { objetos punzocortantes } \\
\text { contaminados }\end{array}$ & $\begin{array}{l}\text { Esta medida aplica para las hojas de bisturí, material de vidrio, agujas o cánulas, } \\
\text { estas deben ser desechadas en los envases apropiados resistentes a } \\
\text { perforaciones, para minimizar la ocurrencia de accidentes y posible } \\
\text { contaminación por parte del personal o los pacientes }\end{array}$ \\
\hline $\begin{array}{l}\text { Vacunación del personal } \\
\text { sanitario }\end{array}$ & $\begin{array}{l}\text { El personal sanitario debe estar inmune o vacunado contra infecciones } \\
\text { transmisibles dentro del ámbito del hospital como hepatitis B, rubéola, } \\
\text { tuberculosis, influenza y varicela, esta medida protege tanto al personal como a } \\
\text { los pacientes vulnerables }\end{array}$ \\
\hline $\begin{array}{ll}\text { Detección } & \text { de } \\
\text { pacientes/personal } & \\
\text { portadores } & \text { de } \\
\text { microorganismos } & \\
\text { multirresistentes } & \end{array}$ & $\begin{array}{l}\text { Esta medida permite que los pacientes/personal potencialmente infecciosos } \\
\text { sean rápidamente identificados y aislados para interrumpir la cadena } \\
\text { epidemiológica de transmisión }\end{array}$ \\
\hline Vigilancia y control de IAAS & $\begin{array}{l}\text { Esta estrategia permite medir la magnitud de los problemas y hacer una } \\
\text { comparación entre hospitales, salas, etc., también permite evaluar el efecto de } \\
\text { cualquier intervención cualquier intervención aplicada para el control de } \\
\text { infecciones }\end{array}$ \\
\hline $\begin{array}{l}\text { Detección y } \\
\text { parcial del } \\
\text { enfermo }\end{array}$ & $\begin{array}{l}\text { El personal sanitario que se sabe que es infeccioso para hepatitis } \mathrm{B} / \mathrm{C} \text { o virus de } \\
\text { inmunodeficiencia humana debe ser excluido de ciertas actividades (por ejemplo, } \\
\text { cirugía) para evitar la infección de sus pacientes. }\end{array}$ \\
\hline $\begin{array}{l}\text { Consideraciones } \\
\text { ingeniería y diseño }\end{array}$ & $\begin{array}{l}\text { Gran parte del personal médico desconocen la complejidad del diseño de una } \\
\text { institución de salud. Factores tan simples como la disponibilidad de lavabos para } \\
\text { lavarse las manos, así como el hacinamiento de los pacientes pueden tener un } \\
\text { efecto significativo en la capacidad del personal para prevenir la transmisión de } \\
\text { infecciones. Las habitaciones individuales deben estar ventiladas } \\
\text { adecuadamente y poseer presión de aire positiva para aislamiento de protección, } \\
\text { mientras que en el caso de infecciones transmitidas por el aire la habitación debe } \\
\text { tener presión neutral o preferiblemente negativa. Idealmente, se debe contar con } \\
\text { suficientes habitaciones individuales para aislar a todos los pacientes con } \\
\text { patologías infecciosas. Se debe suministrar aire filtrado a las salas de aislamiento } \\
\text { y se debe controlar la dirección del flujo de aire en los diferentes ambientes, el } \\
\text { aire debe circular de "limpio" a "sucio" (es decir, de las zonas con muy bajo grado } \\
\text { de contaminación a las zonas con alta carga de contaminación). Los suministros } \\
\text { de agua hospitalaria y las torres de enfriamiento que forman parte del sistema de } \\
\text { aire acondicionado deben mantenerse libres de microorganismos cono } \\
\text { Pseudomonas y Legionella. }\end{array}$ \\
\hline Educación continua & $\begin{array}{l}\text { Se deben diseñar e implementar programas de capacitación del personal } \\
\text { relacionados con las conductas, técnicas y procedimiento a implementar en la } \\
\text { institución, su periodicidad debe ser variable y adecuada a las características del } \\
\text { equipo de salud y el nivel de atención que brindan. La educación continua del } \\
\text { personal tanto la programada como la incidental, tiene un efecto multiplicador en } \\
\text { relación con las políticas y guías institucionales y ayuda enormemente a general } \\
\text { los cambios de conducta necesarios }\end{array}$ \\
\hline
\end{tabular}

MRSA: Staphylococcus aureus resistente a la meticilina

Es importante destacar diferentes estudios que han evaluado la eficiencia o éxito de ciertas medidas implementadas para el control de las IAAS. Pronovost y col. (89), reportan su experiencia en la reducción sostenida en el tiempo de cuadros de bacteriemia secundaria a infección de catéteres intravasculares en unidades de terapia intensiva, la intervención realizada fue simplemente la implementación de una lista de verificación previo a la inserción del catéter, la cual incluía la utilización de medidas de barrera máxima previo a la inserción del catéter, la adecuada higiene de las manos, la asepsia de la piel con un antiséptico adecuado, la retirada de catéteres no necesarios y la no inserción de catéteres de vía femoral, salvo en situaciones de emergencia. Esta experiencia ha logrado reducir el número de IAAS asociadas a dispositivos intravasculares y lo más importante, ha salvado miles de vidas, la experiencia fue trasladada a diferentes países de Europa bajo el nombre de "Bacteriemia Zero" (90), experiencias como estas contribuyen de manera significativa al control de determinadas IAAS. 
Recientemente, el control de infecciones se ha interpretado en un contexto más amplio que permite asegurar la seguridad del paciente, lo que ha hecho que el control de IAAS dependa de un "paquete de medidas" o diferentes intervenciones y medidas de control complementarias (91) que incluyen prácticas de prevención basadas en evidencia, por ejemplo, en el caso de neumonía asociada a ventilación mecánica el paquete de medidas incluye

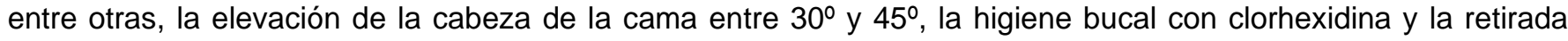
periódica de la sedación.

\section{Perspectivas a futuro}

Los cambios de conducta por parte del personal que labora en una institución de salud contribuyen a la disminución de la incidencia de IAAS y por ende a la reducción de las tasas mortalidad y morbilidad, así como con el decremento de los costos relacionados con la atención en salud, incrementando la seguridad de los pacientes (92). Adicionalmente el incremento en la participación del personal y la implementación de nuevas tecnologías como el uso de dispositivos médicos impregnados con antibacterianos o antisépticos, el uso de ultrasonido para la inserción de catéteres venosos centrales y vestimenta impregnada con clorhexidina han sido bien recibidas para mejorar la práctica del todo el personal de salud responsable del cuidado del paciente (93).

A pesar de todas estas innovaciones en el control y prevención de las IAAS, el lavado de manos continúa siendo el procedimiento de prevención más importante en los hospitales. Los profesionales de la salud frecuentemente se quejan sobre las complicaciones o dificultades para realizar un adecuado lavado de manos, las principales quejas son la resequedad de la piel de las manos, daños causados por el detergente, entre otras. Los profesionales indican que el procedimiento de lavado de manos consume grandes cantidades de tiempo y produce interrupciones en sus labores rutinarias de atención al paciente (94). Diferentes estudios realizados en Europa y Estados Unidos han demostrado el lavado frecuente y repetido de las manos (con agua y jabón o clorhexidina) por parte del personal de salud se cumple en la mayoría de los hospitales solo en un 50\% de los casos $(95,96)$.

Voss y Widmer (95) realizaron un estudio para calcular el tiempo empleado por el personal de salud en el lavado de manos en contraposición con la aplicación de alcohol-gel, los resultados demostraron que el lavado de manos consume de 40 a 80 segundos, mientras que la aplicación de alcohol-gel solo 20 segundos, calculan que en una guardia de 24 horas la técnica del lavado de manos consume al personal de salud aproximadamente 16 horas de su tiempo mientras que la aplicación de alcohol solo 3 horas, indican que el cumplimiento del lavado de manos en un $100 \%$ interfiere con las actividades rutinarias del personal de salud y de allí la dificultad de su cumplimiento, por otra parte indican que la aplicación de alcohol-gel consume un lapso de tiempo mucho menor proporcionando un índice de seguridad aceptable, por lo que es más probable de cumplir en un $100 \%$ sin que se afecte la calidad de la atención brindada al paciente. Aunado al problema del tiempo, en unidades de alta complejidad es muy fácil omitir el lavado de manos debido al exceso de trabajo del personal, otro factor contribuyente es el hecho de ubicar a los pacientes en habitaciones individuales lo que hace difícil supervisar el cumplimiento de esta medida $(92,94)$.

Una de las estrategias implementadas en la actualidad para incrementar el cumplimiento del lavado de manos es la reducción del tiempo necesario para realizar esta tarea, una alternativa propuesta es la sustitución del lavado de manos por el uso de alcohol-gel o sustituir este por clorhexidina, para de esta manera mejorar el cumplimiento de esta medida $(92,94)$. Los estudios más recientes han demostrado que la inclusión de tecnologías como contadores electrónicos y video cámaras para el monitoreo con el fin de proporcionar retroalimentación en tiempo real a los profesionales de la salud sobre el lavado de manos han mejorado el complimiento de esta actividad (97). También se ha descrito el uso de identificadores de radiofrecuencias que no requieren internet para el monitoreo sin supervisión del lavado de manos, este sistema interactúa con el profesional de la salud y ha permitido mejorar el cumplimiento del lavado de manos (98).

\section{Conclusiones}

Las IAAS representan una causa importante y significativa de mortalidad y morbilidad, también son responsable de alargar la estancia de los pacientes y aumentar los costos asociadas a servicios de salud. Debido a las características de los pacientes y el uso frecuente de dispositivos invasivos, el ser internado en unidades de cuidados críticos o intensivos proporciona el doble de riesgo para adquirir estas infecciones al compararlo con los pacientes internados en otros servicios o salas.

Un tercio de estas infecciones son prevenibles, a pesar de que algunas probablemente son inevitables, se ha demostrado que la aplicación de medidas estándar de control conduce a una mejora significativa de la incidencia de estas. La introducción de mejoras en las técnicas y procedimientos, así como de los "paquetes de medidas" para cada procedimiento invasivo o intervención que se realiza al paciente han demostrado mejorar los resultados y la seguridad de los pacientes al reducir la incidencia de IAAS. Sin embargo, todas estas medidas necesitan el 
compromiso de cada nivel del sistema de salud, este debe ir desde el nivel político-administrativo hasta el nivel del personal que interactúa directamente con el paciente.

El aumento de IAAS en nuestros hospitales y el incremento de la resistencia a los antibióticos ha hecho difícil alcanzar la meta de disminución de las tasas de IAAS. Sin embargo, la aplicación de medidas adecuadas y correctas para la prestación de atención diseñadas por comités de control de infecciones, así como el control adecuado de la transmisión utilizando guías o lineamientos de uso racional de antibióticos que permitan reducir la aparición de microorganismos multirresistentes, pueden contribuir significativamente a reducir de manera eficaz la incidencia de IAAS. La aplicación de métodos eficaces de vigilancia siguiendo los lineamientos internacionales del Organización Mundial de la Salud, así como el adecuado entrenamiento y capacitación del personal de salud en materia de bioseguridad, manejo adecuado de desechos biológicos, reformas en los sistemas de salud y concienciar al público en general sobre este problema de salud pública que representan las IAAS son elementos, que deben considerase para tratar de reducir la incidencia de IAAS en nuestras instituciones prestadoras de servicios de salud, todo con el fin de proporcionar una atención sanitaria segura, eficiente y de calidad que permita mejorar la calidad de vida de nuestras poblaciones.

\section{Conflicto de intereses}

Ninguno declarado por los autores.

\section{Financiación}

Autofinanciado.

\section{Referencias}

1. Selwyn S. Hospital infection: the first 2500 years. J Hosp Infect [Internet]. 1991 Jun;18 Suppl A:5-64. Available from: https://pubmed.ncbi.nlm.nih.gov/1679822 DOI: 10.1016/0195-6701(91)90004-r

2. Smith PW, Watkins K, Hewlett A. Infection control through the ages. Am J Infect Control [Internet]. 2011/07/23. 2012 Feb;40(1):35-42. Available from: https://pubmed.ncbi.nlm.nih.gov/21783278 DOI: 10.1016/j.ajic.2011.02.019

3. Ostrowsky B. Epidemiology of Healthcare-Associated Infections. In: Jarvis WR, editor. Bennett \& Brachman's Hospital Infections. 5th ed. Piladelphia-USA Lippincott Williams \& Wilkins; 2007:3-23.

4. Filetoth Z. Hospital Adquired Infection Causes and Control. UK: Whurr Publishers Ltd; 2003.

5. Breathnach AS. Nosocomial infections and infection control. Medicine (Baltimore) [Internet]. 2013;41(11):649-653. Available from: http://www.sciencedirect.com/science/article/pii/S1357303913002466 DOI: https://doi.org/10.1016/j.mpmed.2013.08.010

6. Gastmeier P. Nosocomial infection surveillance and control policies. Curr Opin Infect Dis [Internet]. 2004 Aug;17(4):295-301. Available from: https://pubmed.ncbi.nlm.nih.gov/15241072 DOI: 10.1097/01.qco.0000136929.75543.8a

7. Jay SJ. Nosocomial infections. Med Clin North Am [Internet]. 1983 Nov;67(6):1251-77. Available from: https://pubmed.ncbi.nlm.nih.gov/6355685 DOI: 10.1016/s0025-7125(16)31152-x

8. Jenkins DR. Nosocomial infections and infection control. Medicine (Baltimore) [Internet]. 2017;45(10):629-633. Available from: http://www.sciencedirect.com/science/article/pii/S1357303917301871 DOI: https://doi.org/10.1016/j.mpmed.2017.07.005

9. Sydnor ERM, Perl TM. Hospital epidemiology and infection control in acute-care settings. Clin Microbiol Rev [Internet]. 2011 Jan;24(1):141-173. Available from: https://pubmed.ncbi.nlm.nih.gov/21233510 DOI: 10.1128/CMR.00027-10

10. Freixas N, Sallés M, García L. Cambios en el control de la infección nosocomial: nuevos retos y competencias de la enfermera de control de infección. Enferm Infecc Microbiol Clin [Internet]. 2009/04/22. 2009 May;27(5):285-289. Available from: https://pubmed.ncbi.nlm.nih.gov/19386388 DOI: 10.1016/j.eimc.2008.01.004 PMID 19386388

11. Medicine I of. To Err Is Human: Building a Safer Health System [Internet]. Kohn LT, Corrigan JM, Donaldson MS, editors. Washington, DC: The National Academies Press; 2000. Available from: https://www.nap.edu/catalog/9728/to-err-is-human-building-a-safer-health-system DOI: 10.17226/9728

12. Centers for Disease Control and Prevention (CDC). NCDC/NHSN surveillance definitions for specific types of infections [Internet]. 2020. Available from: https://www.cdc.gov/nhsn/pdfs/pscmanual/17pscnosinfdef_current.pdf

13. Center for Diseases Control and Prevention. Identifying Healthcare-associated Infections (HAI) for NHSN Surveillance [Internet]. 2020 [cited 2020 Feb 23]. Available from: https://www.cdc.gov/nhsn/PDFs/pscManual/2PSC_IdentifyingHAls_NHSNcurrent.pdf

14. Friedman ND, Kaye KS, Stout JE, McGarry SA, Trivette SL, Briggs JP, et al. Health care--associated bloodstream infections in adults: a reason to change the accepted definition of community-acquired infections. Ann Intern Med [Internet]. 2002;137(10):791-797. Available from: https://pubmed.ncbi.nlm.nih.gov/12435215 DOI: 10.7326/0003-4819-137-10-200211190-00007

15. Olaechea PM, Insausti J, Blanco A, Luque P. Epidemiología e impacto de las infecciones nosocomiales [Internet]. Vol. 34, Medicina Intensiva. 2010:25667. Available from: www.elsevier.es/medintensiva DOI: 10.1016/j.medin.2009.11.013

16. Purssell E. Preventing nosocomial infection in paediatric wards. J Clin Nurs [Internet]. 1996;5(5):313-318. Available from: https://pubmed.ncbi.nlm.nih.gov/8932032 DOI: 10.1111/jocn.1996.5.5.313

17. Anonimous. Charaka-Samhitu (c. 4th Century B.C.). Calcuta: Privately printed; $1888.168-169$ p.

18. Major R. A history of medicine. Oxford: Blackwell; 1954. 294-321 p.

19. Stromayr C. Die hundschrift des schnidt und uugenurztes. Cuspur Stromayr [Practicu copiosa]. W von B, editor. Berlin: Idra-Verlagsanstalt; 1925.

20. Madigan MT, Bender KS, Buckley DH, Sattley WM, Stahl DA. Brock Biology of Microorganisms [Internet]. 15th ed. Harlow: Pearson Education, Inc.; 2019. 1058 p. (Biology of microorganisms). Available from: https:/www.pearson.com/nl/en_NL/higher-education/subject-catalogue/biology/Brock-Biology-ofMicroorganisms-Madigan.html?tab=about

21. Moledo L, Magnani E. Diez teorías que conmovieron al mundo: de Copérnico al big bang. Buenos Aires: Capital Intelectual; 2009.237 p.

22. Perez Montoya LH, Zurita Villarroel IM, Pérez Rojas N, Patiño Cabrera N, Calvimonte OR. Infecciones Intrahospitalarias: Agentes, Manejo Actual y Prevención. Rev Científica Cienc Médica [Internet]. 2010;13(2):90-4. Available from: http://www.scielo.org.bo/pdf/rccm/v13n2/a09.pdf

23. lacovelli V, Gaziev G, Topazio L, Bove P, Vespasiani G, Finazzi Agrò E. Nosocomial urinary tract infections: A review. Urologia [Internet]. $2014 / 11 / 12$. 2014;81(4):222-227. Available from: https://pubmed.ncbi.nlm.nih.gov/25451882 DOI: 10.5301/uro.5000092

24. Morales Pérez C, Fresneda Septien G, Guanche Garcell H. Prevalencia puntual de infección nosocomial. Revista Cubana de Enfermería. 2001.17:84-89. Disponible en: http://scielo.sld.cu/scielo.php?script=sci_arttext\&pid=S0864-03192001000200003

25. Zaragoza R, Ramírez P, López-Pueyo MJ. Infección nosocomial en las unidades de cuidados intensivos. Enferm Infecc Microbiol Clin [Internet]. 2014/03/21. 2014;32(5):320-7. Available from: https://pubmed.ncbi.nlm.nih.gov/24661994 DOI: 10.1016/j.eimc.2014.02.006

26. Li Y, Gong Z, Lu Y, Hu G, Cai R, Chen Z. Impact of nosocomial infections surveillance on nosocomial infection rates: A systematic review. Int J Surg [Internet]. 2017/05/03. 2017;42:164-169. Available from: https://pubmed.ncbi.nlm.nih.gov/28476543 DOI: 10.1016/j.ijsu.2017.04.065

27. Hughes JM. Nosocomial infection surveillance in the United States: historical perspective. Infect Control [Internet]. 1987;8(11):450-3. Available from: https://pubmed.ncbi.nlm.nih.gov/2828259 DOI: 10.1017/s0195941700069769 
28. Bassi GL, Ferrer M, Marti JD, Comaru T, Torres A. Ventilator-associated pneumonia. Semin Respir Crit Care Med [Internet]. 2014/08/11. 2014;35(4):469_ 81. Available from: https://pubmed.ncbi.nlm.nih.gov/25111643 DOI: 10.1055/s-0034-1384752

29. Cordero Ruíz DM, García Pérez AL, Barreal González RT, Jiménez Armada J, Rojas Hernández N. Comportamiento de la infección nosocomial en las unidades de terapia en un período de 5 años. Revista Cubana de Higiene y Epidemiología. 2002.40:79-88. Disponible en: http://scielo.sld.cu/scielo.php?script=sci_arttext\&pid=S1561-30032002000200001

30. Vaqué J, Rosselló J, Arribas JL. Prevalence of nosocomial infections in Spain: EPINE study 1990-1997. J Hosp Infect [Internet]. 1999;43:S105-11. Available from: https://doi.org/10.1016/S0195-6701(99)90073-7 DOI: 10.1016/S0195-6701(99)90073-7 PMID 10658766

31. European Centre for Disease Prevention and Control. Point prevalence survey of healthcare-associated infections and antimicrobial use in European acute care hospitals ECDC - PPS validation protocol version 3.1.2 [Internet]. Stockholm; $2019 . \quad$ Available from: https://www.ecdc.europa.eu/sites/default/files/documents/PPS-HAI-AMR-protocol.pdf DOI: 10.2900/444036

32. Klevens RM, Edwards JR, Richards Jr CL, Horan TC, Gaynes RP, Pollock DA, et al. Estimating health care-associated infections and deaths in U.S hospitals, 2002. Public Health Rep [Internet]. 2007;122(2):160-6. Available from: https://pubmed.ncbi.nlm.nih.gov/17357358 DOI: $10.1177 / 003335490712200205$

33. Zhang Y, Du M, Johnston JM, Andres EB, Suo J, Yao H, et al. Incidence of healthcare-associated infections in a tertiary hospital in Beijing, China: results from a real-time surveillance system. Antimicrob Resist Infect Control [Internet]. 2019;8(1):145. Available from: https://doi.org/10.1186/s13756-019-05827 DOI: $10.1186 / \mathrm{s} 13756-019-0582-7$

34. Safdar N, Dezfulian C, Collard HR, Saint S. Clinical and economic consequences of ventilator-associated pneumonia: a systematic review. Crit Care Med [Internet]. 2005;33(10):2184-93. Available from: https://pubmed.ncbi.nlm.nih.gov/16215368 DOI: 10.1097/01.ccm.0000181731.53912.d9

35. Kirkland KB, Briggs JP, Trivette SL, Wilkinson WE, Sexton DJ. The impact of surgical-site infections in the 1990s: attributable mortality, excess length of hospitalization, and extra costs. Infect Control Hosp Epidemiol [Internet]. 1999;20(11):725-730. Available from: https://pubmed.ncbi.nlm.nih.gov/10580621 DOI: $10.1086 / 501572$

36. Douglas SI. The Direct Medical Costs of Healthcare-Associated Infections in U.S. Hospitals and the Benefits of Prevention [Internet]. 2009. Available from: https://www.cdc.gov/HAl/pdfs/hai/Scott_CostPaper.pdf

37. Umscheid CA, Mitchell MD, Doshi JA, Agarwal R, Williams K, Brennan PJ. Estimating the proportion of healthcare-associated infections that are reasonably preventable and the related mortality and costs. Infect Control Hosp Epidemiol [Internet]. 2011;32(2):101-14. Available from: https://pubmed.ncbi.nlm.nih.gov/21460463 DOI: 10.1086/657912

38. Pujol M, Limón E. Epidemiología general de las infecciones nosocomiales. Sistemas y programas de vigilancia. Enferm Infecc Microbiol Clin [Internet]. 2013;31(2):108-13. Available from: https://www.elsevier.es/es-revista-enfermedades-infecciosas-microbiologia-clinica-28-articulo-epidemiologia-generallas-infecciones-nosocomiales--S0213005X13000025 DOI: 10.1016/j.eimc.2013.01.001

39. Edwardson S, Cairns C. Nosocomial infections in the ICU. Anaesth Intensive Care Med [Internet]. 2019;20(1):14-8. Available from: http://www.sciencedirect.com/science/article/pii/S1472029918302509 DOI: https://doi.org/10.1016/j.mpaic.2018.11.004

40. Vincent J-L. Nosocomial infections in adult intensive-care units. Lancet. 2003;361(9374):2068-77. Available from: http://www.sciencedirect.com/science/article/pii/S0140673603136446 DOI: https://doi.org/10.1016/S0140-6736(03)13644-6

41. Appelgren P, Hellström I, Weitzberg E, Söderlund V, Bindslev L, Ransjö U. Risk factors for nosocomial intensive care infection: a long-term prospective analysis. Acta Anaesthesiol Scand [Internet]. 2001 Jul;45(6):710-9. Available from: https://onlinelibrary.wiley.com/doi/abs/10.1034/j.13996576.2001.045006710.x?sid=nIm\%3Apubmed DOI: 10.1034/j.1399-6576.2001.045006710.x PMID 11421829

42. Clark R, Powers R, White R, Bloom B, Sanchez P, Benjamin Jr DK. Nosocomial infection in the NICU: a medical complication or unavoidable problem? J Perinatol [Internet]. 2004;24(6):382-8. Available from: https://pubmed.ncbi.nlm.nih.gov/15116140 DOI: 10.1038/sj.jp.7211120

43. Donowitz LG. Nosocomial infection in neonatal intensive care units. Am J Infect Control [Internet]. 1989;17(5):250-7. Available from: https://pubmed.ncbi.nlm.nih.gov/2683884 DOI: 10.1016/0196-6553(89)90171-5

44. Eickhoff TC. Airborne nosocomial infection: a contemporary perspective. Infect Control Hosp Epidemiol [Internet]. 1994;15(10):663-672. Available from: https://pubmed.ncbi.nlm.nih.gov/7844338 DOI: 10.1086/646830

45. Maki DG. Risk factors for nosocomial infection in intensive care. "Devices vs nature" and goals for the next decade. Arch Intern Med [Internet]. 1989;149(1):30-35. Available from: https://pubmed.ncbi.nlm.nih.gov/2643417 DOI: 10.1001/archinte.149.1.30

46. Lebeque Pérez Y, Morris Quevedo HJ, Calás Viamonte N. Infecciones nosocomiales: incidencia de la Pseudomonas aeruginosa. Revista Cubana de Medicina.2006.45.

47. Wieland K, Chhatwal P, Vonberg R-P. Nosocomial outbreaks caused by Acinetobacter baumannii and Pseudomonas aeruginosa: Results of a systematic review. Am J Infect Control [Internet]. 2018/02/02. 2018;46(6):643-648. Available from: https://pubmed.ncbi.nlm.nih.gov/29398072 DOI: 10.1016/j.ajic.2017.12.014

48. Khan HA, Baig FK, Mehboob R. Nosocomial infections: Epidemiology, prevention, control and surveillance. Asian Pac J Trop Biomed [Internet]. 2017;7(5):478-482. Available from: http://www.sciencedirect.com/science/article/pii/S2221169116309509 DOI: https://doi.org/10.1016/j.apjtb.2017.01.019

49. Alonso-Aguilar NM, Juarez-Enriquez SR, Castro-Escarpulli G, Rivera G, Bocanegra-Garcia V, Guo X, et al. Aetiology and Significance of Hospital-Acquired Infections in Mexico. Clin Lab [Internet]. 20171;63(2):207-218. Available from: https://pubmed.ncbi.nlm.nih.gov/28182358 DOI: 10.7754/Clin.Lab.2016.151119

50. Weiner-Lastinger LM, Abner S, Edwards JR, Kallen AJ, Karlsson M, Magill SS, et al. Antimicrobial-resistant pathogens associated with adult healthcareassociated infections: Summary of data reported to the National Healthcare Safety Network, 2015-2017. Infect Control Hosp Epidemiol [Internet]. 2019/11/26. 2020;41(1):1-18. Available from: https://www.cambridge.org/core/article/antimicrobialresistant-pathogens-associated-with-adulthealthcareassociated-infections-summary-of-data-reported-to-the-national-healthcare-safety-network-

20152017/8172ED836D43D153047F480781E420C1 DOI: 10.1017/ice.2019.296

51. Blot S, Depuydt P, Vandewoude K, De Bacquer D. Measuring the impact of multidrug resistance in nosocomial infection. Curr Opin Infect Dis [Internet]. 2007;20(4):391-396. Available from: https://pubmed.ncbi.nlm.nih.gov/17609598 DOI: 10.1097/QC0.0b013e32818be6f7

52. Santajit S, Indrawattana N. Mechanisms of Antimicrobial Resistance in ESKAPE Pathogens. Biomed Res Int [Internet]. 2016/05/05. 2016;2016:2475067. Available from: https://pubmed.ncbi.nlm.nih.gov/27274985 DOI: 10.1155/2016/2475067

53. Xia J, Gao J, Tang W. Nosocomial infection and its molecular mechanisms of antibiotic resistance. Biosci Trends [Internet]. 2016/02/11. 2016;10(1):1421. Available from: https://pubmed.ncbi.nlm.nih.gov/26877142 DOI: 10.5582/bst.2016.01020

54. Gómez-Gamboa L, Núñez-Chacín D, Perozo-Mena A, Bermúdez-González J, Marín M. Staphylococcus aureus con resistencia múltiple a los antibióticos (MDR) en un Hospital de Maracaibo-Venezuela. Kasmera. 2016;44(1):53-65. Disponible en: https://produccioncientificaluz.org/index.php/kasmera/article/view/21302

55. Castellano MJ, Perozo AJ, Parra AM, Ginestre MM, Rincón GC. Susceptibilidad antimicrobiana y diseminación policlonal de cepas de Staphylococcus aureus. Rev Chil infectología. 2014;31:165-172. Disponible en: https://scielo.conicyt.cl/scielo.php?script=sci_abstract\&pid=S0716$10182014000200007 \&$ Ing $=$ es\&nrm=iso

56. Chang H-H, Dordel J, Donker T, Worby CJ, Feil EJ, Hanage WP, et al. Identifying the effect of patient sharing on between-hospital genetic differentiation of methicillin-resistant Staphylococcus aureus. Genome Med [Internet]. 2016;8(1):18. Available from: https://doi.org/10.1186/s13073-016-0274-3 DOI: 10.1186/s13073-016-0274-3

57. Reynolds C, Quan V, Kim D, Peterson E, Dunn J, Whealon M, et al. Methicillin-resistant Staphylococcus aureus (MRSA) carriage in 10 nursing homes in Orange County, California. Infect Control Hosp Epidemiol [Internet]. 2010/11/18. 2011;32(1):91-93. Available from: https://pubmed.ncbi.nlm.nih.gov/21087124 DOI: 10.1086/657637

58. López-Urrutia L, de Frutos M, Oteo J, Eiros JM. Vancomycin-resistant Enterococcus faecium ST17 outbreak in a Neonatal Unit TT - Brote por Enterococcus faecium ST17 resistente a glucopéptidos en una Unidad de Neonatología. Enferm Infecc Microbiol Clin [Internet]. 2017/08/12. 2018;36(3):198-200. Available from: https://pubmed.ncbi.nlm.nih.gov/28807390 DOI: 10.1016/j.eimc.2017.07.002

59. Raza T, Ullah SR, Mehmood K, Andleeb S. Vancomycin resistant Enterococci: A brief review. J Pak Med Assoc [Internet]. 2018;68(5):768-72. Available from: https://pubmed.ncbi.nlm.nih.gov/29885179 
60. Alvarez Lerma F, Palomar M, Insausti J, Olaechea P, Alcalá MA, Blanco A, et al. Enterococcal infections in critically ill patients admitted to ICU TT Infección por enterococo en pacientes críticos ingresados en la UCI. Med Clin (Barc) [Internet]. 2003;121(8):281-286. Available from: https://pubmed.ncbi.nlm.nih.gov/14499081 DOI: 10.1016/s0025-7753(03)73919-0

61. Perozo Mena AJ, Castellano González MJ, Ginestre Pérez MM, Rincón Villalobos Gresleida C. Resistencia a Vancomicina en Cepas de Enterococcus faecium Aisladas en un Hospital Universitario. Kasmera. 2011;39(1):7-17. Disponible en: https://produccioncientificaluz.org/index.php/kasmera/article/view/4869

62. Perozo Mena A, Castellano González M, Ginestre Pérez M, Harris B. Caracterización molecular y detección de Betalactamasas de espectro extendido en cepas de E. coli y K. pneumoniae aisladas en las Unidades de Cuidados Intensivos de un Hospital Universitario. Kasmera [Internet]. 2007;35(2):91-106. Available from: http://www.produccioncientificaluz.org/revistas/index.php/kasmera/article/view/4788

63. Guzmán M, Alonso G. Caracterización de B-lactamasas de espectro extendido (BLEE) en cepas nosocomiales de K. pneumoniae. Sucre-Venezuela. Invest Clin. 2009;50:419-431. Disponible en: http://ve.scielo.org/scielo.php?script=sci arttext\&pid=S0535-51332009000400002

64. Guzmán L M, Rodríguez E, Antón C K, Silva S, Navarro J, Lastra L, et al. Genes blaTEM, blaSHV y blaCTX-M en enterobacterias productoras de blactamasas de espectro extendido aisladas de pacientes con infección intrahospitalaria. Invest Clin. 2013;54:235-245. Disponmible en: http://ve.scielo.org/scielo.php?script=sci_arttext\&pid=S0535-51332013000300002

65. Sandrea-Toledo L, Paz-Montes A, Piña-Reyes E, Perozo-Mena A. Enterobacterias productoras de B-lactamasas de espectro extendido aisladas de hemocultivos en un Hospital Universitario de Venezuela. Kasmera. 2007;35(1):15-25. Disponible en: https://produccioncientificaluz.org/index.php/kasmera/article/view/4781

66. García J, Rodríguez E, Carpio C, Albarado Y L, Salazar E, Flores F E, et al. Susceptibilidad Antimicrobiana in vitro de enterobacterias nosocomiales productoras de betalactamasas de espectro expandido, Cumaná, estado Sucre. Kasmera. 2009;37(1):38-50. Disponible en: https://produccioncientificaluz.org/index.php/kasmera/article/view/4838

67. Torres L, Gagliotta V, Torres O, Benítez M. B-Lactamasas de Espectro Expandido en Enterobacterias aisladas en Centros de Salud de Caracas. Rev la Soc Venez Microbiol. 2006;26:80-88. Disponible en: http://ve.scielo.org/scielo.php?script=sci_arttext\&pid=S1315-25562006000200004

68. Tedesco-Maiullari RM, Guevara A. Epidemiología molecular de Klebsiella pneumoniae productora de B-lactamasas de espectro extendido. Rev la Soc Venez Microbiol. 2012;32:101-106. Disponible en: http://ve.scielo.org/scielo.php?script=sci_arttext\&pid=S1315-25562012000200005

69. Gaitán C SL, Espinal M PA. Caracterización molecular de Escherichia coli y Klebsiella pneumoniae productores de ß-lactamasas de espectro extendido en hospitales de la Región Caribe, Colombia. Rev Chil infectología. 2009;26:239-246. Disponible en: https://scielo.conicyt.cl/scielo.php?script=sci arttext\&pid=S0716-10182009000400006

70. Fernández-Verdugo A, Fernández J, Escudero D, Cofiño L, Forcelledo L, Telenti M, et al. Epidemiological surveillance for multidrug-resistant microorganisms in a general ICU TT - Vigilancia epidemiológica para microorganismos multirresistentes en una UCI polivalente. Rev Esp Quimioter [Internet]. 2017/04/05. 2017 Jun;30(3):201-206. Available from: https://pubmed.ncbi.nlm.nih.gov/28422471

71. Amudhan MS, Sekar U, Kamalanathan A, Balaraman S. bla(IMP) and bla(VIM) mediated carbapenem resistance in Pseudomonas and Acinetobacter species in India. J Infect Dev Ctries [Internet]. 2012;6(11):757-762. Available from: https://pubmed.ncbi.nlm.nih.gov/23277500 DOI: 10.3855/jidc.2268

72. Ghaith DM, Mohamed ZK, Farahat MG, Aboulkasem Shahin W, Mohamed HO. Colonization of intestinal microbiota with carbapenemase-producing Enterobacteriaceae in paediatric intensive care units in Cairo, Egypt. Arab J Gastroenterol [Internet]. 2019/02/04. 2019;20(1):19-22. Available from: https://pubmed.ncbi.nlm.nih.gov/30733176 DOI: 10.1016/j.ajg.2019.01.002

73. Ahmad N, Ali SM, Khan AU. Detection of New Delhi Metallo- - -Lactamase Variants NDM-4, NDM-5, and NDM-7 in Enterobacter aerogenes Isolated from a Neonatal Intensive Care Unit of a North India Hospital: A First Report. Microb Drug Resist [Internet]. 2017/06/14. 2018;24(2):161-165. Available from: https://pubmed.ncbi.nlm.nih.gov/28613981 DOI: 10.1089/mdr.2017.0038

74. Ramadan RA, Gebriel MG, Kadry HM, Mosallem A. Carbapenem-resistant Acinetobacter baumannii and Pseudomonas aeruginosa: characterization of carbapenemase genes and E-test evaluation of colistin-based combinations. Infect Drug Resist [Internet]. 2018;11:1261-1269. Available from https://pubmed.ncbi.nlm.nih.gov/30197524 DOI: 10.2147/IDR.S170233

75. Perozo Mena AJ, Castellano González MJ, Ling Toledo E, Arraiz N, Perozo M, Armindo J, et al. Detección fenotípica de metalobetalactamasas en aislados clínicos de Pseudomonas aeruginosa. Kasmera [Internet]. 2012;40(2):113-121. Available from: http://www.produccioncientificaluz.org/revistas/index.php/kasmera/article/view/4936

76. Gomez-Gamboa L, Villasmil J, Perozo-Mena A, Bermudez-Gonzalez JL, Zabala I. Emergencia de Acinetobacter baumannii con resistencia extrema a los antibióticos en un Hospital de Maracaibo, Venezuela. [Internet]. Sociedad Venezolana de Bioanalistas Especialistas; 2016. Available from: http://190.169.94.12/ojs/index.php/rev_ACSVBE/article/view/10222

77. Gómez-Gamboa L, Perozo-Mena A, Lugo J, Bermúdez-González J, Zabala I, Morales E. Carbapenemasas KPC en Enterobacteriaceae aisladas en un Hospital de Maracaibo, Venezuela. Kasmera. 2014.42(1):89-104. Disponible en: http://produccioncientificaluz.org/index.php/kasmera/article/view/19495

78. Gomez-Gamboa L, Barrios-Camacho H, Duran-Bedolla J, Sánchez-Perez A, Reyna-Flores F, Perozo-Mena A, et al. Molecular and genetic characterization of carbapenemase-producing bacteria in Venezuela. J Chemother [Internet]. 2019;31(6):349-353. Available from https://doi.org/10.1080/1120009X.2019.1607452 DOI: 10.1080/1120009X.2019.1607452

79. Perozo-Mena A, Castellanos-González M, Ling E, Gómez L, Ginestre M, Rincón G. Presencia de carbapenemasa tipo KCP en aislados clínicos de K. pneumoniae de pacientes de unidades de cuidados intensivos. Kasmera. 2016;44(1):44-52. Disponible en: https://produccioncientificaluz org/index.php/kasmera/article/view/21300

80. Perozo A, Calvo B, Mesa L, Pineda M. Susceptibilidad a fluconazol y voriconazol por el método de difusión, de cepas de Candida, aisladas de hemocultivos en Maracaibo, Venezuela . Vol. 39, Kasmera . scielon ; 2011:114-122. Disponible en: https://produccioncientificaluz.org/index.php/kasmera/article/view/4881

81. Epelbaum O, Chasan R. Candidemia in the Intensive Care Unit. Clin Chest Med [Internet]. 2017/06/16. 2017;38(3):493-509. Available from: https://pubmed.ncbi.nlm.nih.gov/28797491 DOI: 10.1016/j.ccm.2017.04.010

82. De Pascale G, Tumbarello M. Fungal infections in the ICU: advances in treatment and diagnosis. Curr Opin Crit Care [Internet]. 2015;21(5):421-429. Available from: https://pubmed.ncbi.nlm.nih.gov/26165502 DOI: 10.1097/MCC.0000000000000230

83. Blot S, Dimopoulos G, Rello J, Vogelaers D. Is Candida really a threat in the ICU? Curr Opin Crit Care [Internet]. 2008;14(5):600-604. Available from: https://pubmed.ncbi.nlm.nih.gov/18787456 DOI: 10.1097/MCC.0b013e32830f1dff

84. Maubon D, Garnaud C, Calandra T, Sanglard D, Cornet M. Resistance of Candida spp. to antifungal drugs in the ICU: where are we now? Intensive Care Med [Internet]. 2014/08/05. 2014;40(9):1241-1255. Available from: https://pubmed.ncbi.nlm.nih.gov/25091787 DOI: 10.1007/s00134-014-3404-7

85. Eyre DW, Sheppard AE, Madder H, Moir I, Moroney R, Quan TP, et al. A Candida auris Outbreak and Its Control in an Intensive Care Setting. N Engl J Med [Internet]. 2018;379(14):1322-1331. Available from: https://pubmed.ncbi.nlm.nih.gov/30281988 DOI: 10.1056/NEJMoa1714373

86. Calvo B, Melo ASA, Perozo-Mena A, Hernandez M, Francisco EC, Hagen F, et al. First report of Candida auris in America: Clinical and microbiological aspects of 18 episodes of candidemia. J Infect [Internet]. 2016;73(4):369-374. Available from: https://doi.org/10.1016/j.jinf.2016.07.008 DOI: 10.1016/j.jinf.2016.07.008

87. Warren JW. Catheter-associated urinary tract infections. Int J Antimicrob Agents [Internet]. 2001;17(4):299-303. Available from: http://www.sciencedirect.com/science/article/pii/S0924857900003599 DOI: https://doi.org/10.1016/S0924-8579(00)00359-9

88. Azanza JR, Barberán J, García-Rodríguez JA, Llinares P, Mensa J, Picazo J, et al. Recommendations for the treatment of nosocomial infections caused by Gram-positive microorganisms TT - Recomendaciones para el tratamiento de las infecciones nosocomiales producidas por microorganismos grampositivos. Rev Esp Quimioter [Internet]. 2004;17(3):271-288. Available from: https://pubmed.ncbi.nlm.nih.gov/15619658

89. Pronovost $\mathrm{P}$, Needham D, Berenholtz S, Sinopoli D, Chu H, Cosgrove S, et al. An Intervention to Decrease Catheter-Related Bloodstream Infections in the ICU. N Engl J Med [Internet]. 2006 28;355(26):2725-2732. Available from: https://doi.org/10.1056/NEJMoa061115 DOI: 10.1056/NEJMoa061115

90. Palomar Martínez M, Álvarez Lerma F, Riera Badía MA, León Gil C, López Pueyo MJ, Díaz Tobajas C, et al. Prevención de la bacteriemia relacionada con catéteres en UCI mediante una intervención multifactorial. Informe del estudio piloto. Med Intensiva [Internet]. 2010;34(9):581-589. Available from: https://www.medintensiva.org/es-prevention-bacteriema-related-with-icu-articulo-S0210569110002238 DOI: 10.1016/j.medin.2010.07.005 
91. Aboelela SW, Stone PW, Larson EL. Effectiveness of bundled behavioural interventions to control healthcare-associated infections: a systematic review of the literature. J Hosp Infect [Internet]. 2007;66(2):101-108. Available from: http://www.sciencedirect.com/science/article/pii/S0195670106005433 DOI: https://doi.org/10.1016/j.jhin.2006.10.019

92. Marra AR, Pavão Dos Santos OF, Cendoroglo Neto M, Edmond MB. Positive Deviance: A New Tool for Infection Prevention and Patient Safety. Curr Infect Dis Rep [Internet]. 2013 Sep 28; Available from: https://pubmed.ncbi.nlm.nih.gov/24078405 DOI: 10.1007/s11908-013-0372-y

93. Latif A, Halim MS, Pronovost PJ. Eliminating Infections in the ICU: CLABSI. Curr Infect Dis Rep [Internet]. 2015;17(7):491. Available from: https://pubmed.ncbi.nlm.nih.gov/26031963 DOI: 10.1007/s11908-015-0491-8

94. Boyce JM, Pittet D, Committee HICPA, Force HHHT. Guideline for Hand Hygiene in Health-Care Settings. Recommendations of the Healthcare Infection Control Practices Advisory Committee and the HICPAC/SHEA/APIC/IDSA Hand Hygiene Task Force. Society for Healthcare Epidemiology of America/Association for Prof. Morb Mortal Wkly Rep [Internet]. 2002;51(RR-16):1-45. Available from: https://pubmed.ncbi.nlm.nih.gov/12418624

95. Voss A, Widmer AF. No time for handwashing!? Handwashing versus alcoholic rub: can we afford 100\% compliance? Infect Control Hosp Epidemiol [Internet]. 1997;18(3):205-208. Available from: https://pubmed.ncbi.nlm.nih.gov/9090551 DOI: 10.1086/647590

96. Pittet D, Mourouga P, Perneger T V. Compliance with handwashing in a teaching hospital. Infection Control Program. Ann Intern Med [Internet] 1999;130(2):126-130. Available from: https://pubmed.ncbi.nlm.nih.gov/10068358 DOI: 10.7326/0003-4819-130-2-199901190-00006

97. Armellino D, Hussain E, Schilling ME, Senicola W, Eichorn A, Dlugacz Y, et al. Using high-technology to enforce low-technology safety measures: the use of third-party remote video auditing and real-time feedback in healthcare. Clin Infect Dis [Internet]. 2011/11/21. 2012;54(1):1-7. Available from: https://pubmed.ncbi.nlm.nih.gov/22109950 DOI: 10.1093/cid/cir773

98. Marra AR, Edmond MB. New technologies to monitor healthcare worker hand hygiene. Clin Microbiol Infect [Internet]. 2014 Jan;20(1):29-33. Available from: https://pubmed.ncbi.nlm.nih.gov/24245809 DOI: 10.1111/1469-0691.12458

Armindo Perozo-Mena (Autor de Correspondencia). ORCID ID: https://orcid.org/0000-0002-0378-7860.

Maribel Josefina Castellano González. ORCID ID: https://orcid.org/0000-0002-1992-8349.

Liliana Patricia Gómez Gamboa. ORCID ID: https://orcid.org/0000-0003-1354-1095.

Enferm Inv. 5(2):48-61 